\title{
A crise do capital e relações de trabalho: considerações sobre "consultorias sociais" em empresas
}

\author{
The capital crisis and labor relations: considerations about \\ "social consulting" in companies
}

Márcia Regina Botão Gomes*

\begin{abstract}
Resumo - Neste artigo, abordaremos especificamente as chamadas "consultorias" especializadas em programas de assistência ao empregado (PAE), que consistem em formas de terceirização e quarteirização do trabalho do assistente social, como expressão dos processos de precarização do trabalho de assistentes sociais em empresas. Trata-se de resultados parciais de nossa pesquisa de doutorado (2015), realizada na Universidade do Estado do Rio de Janeiro, que teve como método de coleta de dados qualitativos entrevistas semiestruturadas e pesquisas bibliográficas de orientação marxista.

Palavras-chave: crise do capital; Serviço Social; consultoria empresarial.

Abstract - In this article, we will specifically address the so-called "consulting services" specialized in Employee Assistance Programs (EAP), consisting in the outsourcing through third- and fourth-party services of social worker positions, as a result of the precariousness process of social work in companies. These are partial results of our doctoral research (2015) held at the Rio de Janeiro State University, that had as qualitative data collection method semi-structured interviews and a Marxist-oriented bibliographical research.

Keywords: capital crisis; social work; business consulting.
\end{abstract}

\section{Introdução}

Nas últimas décadas do século XX e no início do século XXI, houve transformações no trabalho dos assistentes sociais. Neste artigo, privilegiaremos algumas mudanças do Serviço Social em empresas, por ter sido nossa área de atuação profissional desde o final da década de 1990 e objeto

\footnotetext{
* Doutora em Serviço Social (UERJ - 2015). Professora do curso de Serviço Social (PUC-Rio). Atualmente pesquisa as novas faces do Serviço Social nas empresas do século XXI: Mudanças nas formas de contratação, organização do trabalho e requisições profissionais. E-mail: mrbotao@yahoo.com.br. ORCID: https://orcid.org/0000-00032672-3672.
} 


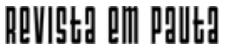

\} A CRISE DO CAPITAL E RELAÇÕES - GOMES, M. R. B. \}

DOI: $10.12957 /$ REP.2019.45241

de pesquisa durante o mestrado na UFRJ (2010) e o doutorado na Uerj (2015). Cabe ressaltar que o universo que compõe o espaço sócio-ocupacional das empresas é amplo e muito diversificado, existindo empresas de grande ou pequeno porte e em diferentes ramos e segmentos de atuação. $\mathrm{O}$ que destacamos neste artigo é um modo específico de precarização do trabalho dos assistentes sociais nas chamadas "consultorias", que se espraiam a partir do final da década de 1990 através das grandes corporações, mas, atualmente, encontram-se em empresas variadas.

Tendo em vista a condição de trabalhadora de empresas multinacionais no período de 1999-2006, e posteriormente como pesquisadora, foi possível identificar mudanças no modo de contratação de trabalhadores, bem como na organização das atividades profissionais. Tais reconfigurações não são isoladas ou endógenas, mas, sim, expressões dos processos de reestruturação produtiva, instaurados no Brasil a partir da década de 1990 e articulados à neoliberalização'.

Do conjunto de mudanças ocorridas no Serviço Social em empresas, destacamos as chamadas "consultorias" especializadas em programas de assistência ao empregado. Essas são formas de terceirização, quarteirização e instauração de um tipo de atendimento social a distância, com possibilidade de contratação para realização de atendimentos presenciais por demanda em caráter de prestação de serviço, que não chegam a 50\% dos casos atendidos, segundo dados fornecidos pela maior empresa de consultoria entrevistada em 2015.

Os resultados parciais da pesquisa têm início no curso de mestrado realizado na UFRJ em 2010, quando foram entrevistadas cinco assistentes sociais vinculadas a empresas de consultoria, sendo quatro especialistas em Serviço Social e uma especialista em programas de assistência social, em que o assistente social é um dos profissionais prestadores de serviços. Diante de novas problemáticas, demos seguimento a essa questão na pesquisa de doutorado, entrevistando nove profissionais, incluindo trabalhadoras de call center, coordenadoras, usuárias dos serviços e contratantes das "consultorias". Além disso, levantamos dados de domínio público em sites de consultorias no eixo Rio-São Paulo.

Trata-se de um serviço limitado, fragmentado por demanda, externo às empresas, composto por um grupo reduzido de pessoas, de menos de dez assistentes sociais, com vínculo empregatício que atendem através de um call center. É complementado por profissionais quarteirizados, chamados de "consultores", que prestam serviço conforme demanda, ultrapassando o número de 3.000 em todo território brasileiro².

Desse modo, a apropriação do termo "consultoria" tem utilidade favorável às empresas que comercializam tais serviços, pois omite perdas

${ }^{1}$ Utilizamos o termo neoliberalização com base em Harvey (2008), que apresenta diferenças entre o discurso sobre o neoliberalismo e sua efetivação real.

${ }^{2}$ Dados decorrentes de nossa pesquisa durante o curso de doutorado em 2015, realizado no Programa de Pós- 


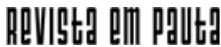

\} A CRISE DO CAPITAL E RELAÇÕES - GOMES, M. R. B. \}

DOI: $10.12957 /$ REP.2019.45241

de direitos trabalhistas e incide diretamente no desenvolvimento das atividades dos assistentes sociais, com consequências para os sujeitos atendidos.

Antunes (2013) demonstra a ampliação de trabalhos submetidos a sucessivos contratos temporários, sem estabilidade, sem registro em carteira, exercidos dentro ou fora do espaço produtivo das empresas, quer em atividades instáveis, quer temporárias, quando não na condição de trabaIhadores desempregados. O capital impulsiona as empresas à flexibilização, incidindo em relações de trabalho, jornada e remuneração, retornando relações e formas de trabalho com características de informalidade. O trabalho contratado e regulamentado, dominante no século XX tem sido substituído por modalidades de "empreendedorismo", "cooperativismo", "trabalho voluntário", entre outros.

Assim, as "consultorias" empresariais, às quais o Serviço Social tem se vinculado profissionalmente de forma precária, foram analisadas considerando a relação entre a totalidade macrossocial e suas particularidades como expressões da crise contemporânea do capital.

Essa crise capitalista implicou a alteração das formas de organização do trabalho, deixando de predominar o padrão fordista-keynesiano, decorrente do pacto social do período posterior à Segunda Guerra Mundial nos países centrais. Adotado sem superar completamente esse modelo anterior, cresceu o chamado toyotismo ou ohnismo, caracterizando o modo de "acumulação flexível", que Harvey (2008) chama de "novo imperialismo" ou acumulação por espoliação.

Para Harvey (2008), o investimento neoliberal feito por segmentos capitalistas visa à restauração do poder de classe. Nesse sentido, a crise do capital - ocorrida nos países centrais a partir do final da década de 1960 e no Brasil, no final da década de 1980 - possui vetores articulados de ordem econômica, política e também cultural, resultando em maior subordinação da classe trabalhadora ao capital. No primeiro item deste artigo, apresentaremos os aspectos gerais dessa crise; em seguida, abordaremos seus rebatimentos para os assistentes sociais em empresas e, por fim, realizaremos breves considerações.

\section{A crise contemporânea do capital}

Para localizar a crise do capital após 1970, apresentaremos alguns elementos essenciais das reflexões de Mandel (1990), Harvey (2004, 2008), Mota (1995, 1998), Netto e Braz (2007), Mészáros (2009) e Fontes (2012), autores que analisam o capitalismo em sua fase madura, considerando a historicidade de seus movimentos, a partir de uma visão crítica da sociedade capitalista e de um referencial teórico marxista. Entendemos que a atual crise do capitalismo não decorre da escassez de recursos, mas da superacumulação da riqueza produzida pela classe dominante. 


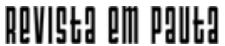

\} A CRISE DO CAPITAL E RELAÇÕES - GOMES, M. R. B. \}

DOI: $10.12957 /$ REP.2019.45241

Para Mandel (1990), as crises do capitalismo são cíclicas e inerentes ao capital, contudo, não são "naturais". Ao contrário, são criadas e recriadas a partir de processos históricos, políticos e culturais, em tentativas de "soluções" capitalistas que recorrem a técnicas anticrises. Porém, essas técnicas possuem limites e prolongam os períodos dessas crises sem superá-las de fato, gerando crises maiores, conforme Mészáros (2009).

Ainda segundo Mandel (1990), a crise pós-1970 foi um exemplo de tentativa de contenção, por parte do capital, utilizando uma política de expansão e controle sucessivos do crédito e visando a um prolongamento da "onda expansiva" do capital naquele período. As medidas utilizadas foram inflacionárias, devido às disparidades das moedas e aos planos políticos e econômicos dos países envolvidos. Essa crise fez o mercado internacional capitalista conhecer a primeira recessão generalizada desde a Segunda Guerra Mundial que golpeou todas as grandes potências imperialistas e retraiu a economia. Em 1975, houve queda da produção industrial e do PIB em todos os grandes países imperialistas. Para fundamentar essa afirmação, Mandel (1990) dedica um capítulo à regularidade e às repetições das crises capitalistas, que possuem, inclusive, espaço e periodicidade semelhantes entre si.

Portanto, a sucessividade das crises no capitalismo torna explícita sua dinâmica instável, mas não natural. Isso porque "as crises são inerentes sob o capitalismo, mas é perfeitamente possível e viável uma organização da economia estruturalmente diferente da organização capitalista, capaz de suprimir as causas da crise" (NETTO; BRAZ, 2007, p. 157). Nesse contexto, os autores se referem à possibilidade de um projeto que considere a história sem naturalizar os acontecimentos, repensando as relações entre os sujeitos. O capitalismo, entretanto, não será superado, justamente em decorrência de suas crises.

De acordo com Mandel (1990), diante do desenvolvimento do capital, dois aspectos refletiram-se nos níveis de emprego da classe trabalhadora. O primeiro refere-se à tecnologia avançada de produção automática e semiautomática de países imperialistas, com desequilíbrio entre produção e emprego produtivo. O segundo aspecto foi a reconstrução do exército industrial de reserva de força de trabalho durante o período pós-guerra, quando mulheres casadas, jovens e trabalhadores imigrantes de países menos industrializados foram incorporados ao grupo de assalariados efetivos. Esse grupo possuía salários reduzidos, restringindo-se a atividades não qualificadas ou insalubres, sendo marginalizado e facilmente descartado (MANDEL, 1990).

Aumento do custo de vida, estagnação da circulação das mercadorias e ociosidade da capacidade de produção explicam o controle de preços pelas grandes empresas para manter as margens de lucro e reduzir sua queda demasiada. Este resultado foi obtido com a cumplicidade de governos, bancos centrais e todo o sistema bancário, com promessas de luta contra a inflação. Posteriormente, políticas anti-inflacionárias foram adotadas 


\section{ReVIStg a d P P PUtD}

\} A CRISE DO CAPITAL E RELAÇÕES - GOMES, M. R. B. \}

DOI: $10.12957 /$ REP.2019.45241

por indicações com base no Consenso de Washington, encontro realizado pelo grupo de economistas integrantes do International Institute for Economy, em 1989, que objetivou estratégias políticas e econômicas para os países latino-americanos. Tais propostas foram utilizadas por organismos internacionais, como o Fundo Monetário Internacional (FMI) e o Banco Mundial, entre outros. Na ocasião, foram estabelecidas condicionalidades para a renegociação da dívida externa dos países em desenvolvimento, adotadas em favor dos grandes grupos capitalistas e com retrocesso das medidas de proteção social alcançadas pelos países. No caso latino-americano, essas medidas têm impactos mais profundos, pois os modelos de proteção social desses países são incompletos, se comparados aos de países desenvolvidos.

Sabemos que o fim do capitalismo não será um resultado automático dos processos de crise, pois, apesar de contraditórias, elas são funcionais a esse modo de produção. Não há capitalismo sem crise e a dinâmica de restauração e crise resulta em reconfiguração do poder econômico e de consequente dominação, mas não a eliminação do modo de produção capitalista. Dessa maneira, a classe trabalhadora sofre os maiores reveses desse processo, com trabalhadores sendo impactados em suas condições de sobrevivência, nas mudanças das relações de trabalho e acesso a serviços fundamentais, além de serem as principais vítimas da violência, incluindo a criminalização da pobreza e das manifestações de resistência social.

A sobrevivência do capitalismo diante das crises tem sido mantida pelo consenso entre as classes e também pela força militar, que controla os grupos contrários às classes dominantes quando os mecanismos de consenso são insuficientes. As análises dos "ajustes espaço-temporais", seu funcionamento e importância nas contradições do próprio capital auxiliam o entendimento da dinâmica de crise e reação capitalistas, discutidas por Harvey (2004), especialmente em tempos de financeirização da economia. Para ele, esses "ajustes temporais" estão relacionados à valorização do capital, embora também aos processos de crise e desvalorização, que não são excludentes, mas constitutivos do capital, com imposição da lei do valor apresentada por Marx (1975) em seu texto fundamental O capital: crítica da economia política.

Tendo isso em vista, a sobreacumulação do capitalismo global tornou-se constante e crônica desde a década de 1970. A volatilidade, como solução, não passou de uma sucessão de tentativas frustradas de ajustes espaço-temporais. Harvey (2004) utiliza a referência de Gowan quando afirma ser essa volatilidade uma estratégia, por parte dos Estados Unidos, de manutenção da hegemonia no capitalismo global, com consequente surgimento de um imperialismo aberto e respaldado por aparatos militares, podendo ser interpretado como fragilidade ou debilidade da hegemonia norteamericana diante das crises e recessões que atacam antes outras regiões. Entretanto, ele acrescenta que "[...] a incapacidade de acumular através da 


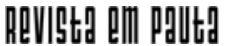

\} A CRISE DO CAPITAL E RELAÇÕES - GOMES, M. R. B. \}

DOI: $10.12957 /$ REP.2019.45241

reprodução ampliada de modo sutentáveltem gerado formas de acumlação por espoliação, traço do novo imperialismo'"...

A ideia do ajuste espaço-temporal consiste na sobreacumulação em um sistema territorial com excedente de trabalho e capital que precisa ser realocado pelos capitalistas. Assim, uma das formas utilizadas é o investimento de capital em projetos de longo prazo (HARVEY, 2004).

Um dos aspectos dessas estratégias é sua dinâmica de transposição dos investimentos atuais para o futuro, em que as mediações das instituições financeiras assumem papel crucial, assim como estatais com capacidade de crédito. Nesse movimento, é gerado o "capital fictício", capaz de transcender o consumo atual para projetos futuros, que prometem ser realizados adiante. Segundo Harvey (2004), quando os investimentos apresentam retorno efetivo para o capital, os valores fictícios podem ser amortizados. Já quando o contrário ocorre, a sobreacumulação pode ser manifestada através de desvalorizações de ativos ou na forma de crise fiscal do Estado, algo que temos observado no Brasil há alguns anos (HARVEY, 2004).

Os países que dependem de empréstimos ou que os acumularam para se manterem tornam-se cada vez mais fragilizados ante o capital especulativo e fictício. Nas décadas iniciais do século XXI, há imposições de desvalorização selvagem em territórios mais vulneráveis. Outro resultado dos ajustes espaço-temporais é o aumento da competição internacional entre países, à medida que surgem vários centros de acumulação concorrentes inseridos em um contexto de sobreacumulação.

Assim, para a conquista de posições de poder no espaço territorial, um elemento fundamental está nas mediações institucionais, que são, ao mesmo tempo, produtoras e produto da dinâmica capitalista. Tais instituições podem ser estatais, supraestatais e financeiras, relevantemente o FMI e o Banco Internacional de Reconstrução e Desenvolvimento (Bird), entre outros.

As autoras Galízia e Pastorini (2006) discutem a relação desses organismos com os países da América Latina no que diz respeito às reformas neoliberais do sistema de proteção social na década de 1990, considerando o surgimento desses organismos, seus objetivos e imposições "sugeridas" para a concessão de recursos em forma de empréstimos. Entretanto, as exigências não se limitaram ao final do século passado, sendo mantidas e intensificadas.

O resultado dessas estratégias, sobretudo do processo de financeirização da economia acompanhada da reestruturação produtiva, foi o aumento do índice de desemprego, bem como da pauperização e perda de direitos por parte da classe trabalhadora. Contudo, essa lógica estadunidense não pode ser considerada simplesmente vitoriosa ou fracassada. Trata-se de um processo complexo, pois os EUA também vivenciam as dificuldades que comprometem todo o conjunto de países que possuem políticas interligadas, o que os leva a financiar seu consumismo e produtivismo para manutenção do mercado de produtos excedentes. 


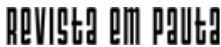

\} A CRISE DO CAPITAL E RELAÇÕES - GOMES, M. R. B. \}

DOI: $10.12957 /$ REP.2019.45241

Para Harvey (2004), as ameaças aos EUA podem representar sinais de transição de poder hegemônico para outra potência econômica. Porém, não significa que essa transição seja pacífica. Ao contrário, as estratégias de guerra e ataques "preventivos" do início dos anos 2000 são recuperadas na era Trump. Apesar disso, sua insuficiência pode gerar outras formas de acumulação, nas quais Harvey (2004) centra sua hipótese de "acumulação por espoliação".

Fontes (2012), por sua vez, problematiza a interpretação de Harvey, que é levado a crer no surgimento de "um novo imperialismo". A autora afirma que, no período atual, permanecem formas de expropriação constitutivas do capital desde sua origem, sendo simultaneamente condição para sua existência e decorrência dela. Nesse sentido, não há novidade, mas um conjunto de reconfigurações, sem contraposição entre "expropriação" e "espoliação". Segundo alguns pressupostos de Harvey (2004), a expropriação em Marx seria um momento original do capital que resultaria em formas de reprodução ampliada; já a acumulação por espoliação seria diferente das formas primitivas e tradicionais de expropriação. Assim, o capitalismo "normalizado" abrandaria as formas especulativas de seus primórdios. Fontes $(2012$, p. 63) discorda, pois,

Marx de fato considerava que, uma vez realizada a violenta expropriação camponesa, a coação econômica 'normalizada' sobre os trabalhadores agora 'livres' substitui a violência aberta. No entanto, em inúmeras passagens $d^{\prime} \mathrm{O}$ capital [...], reafirma que a expansão das relações sociais capitalistas pressupõe sempre sucessivas expropriações, para além daqueles trabalhadores já 'liberados' (inclusive mencionando a expropriação de capitalistas menores).

A autora enfatiza que as formas "normalizadas" do capital nunca dispensaram especulação, roubo e outros mecanismos de expropriação, ainda que judicializados, nas relações entre capital e trabalho, sobretudo nos países centrais. Mas, mesmo neles, a classe trabalhadora vem sofrendo maiores índices de expropriação de direitos.

Então, o que há de novo nesses processos que pode levar a acreditar que existe "um novo imperialismo", como sugere Harvey (2004), ou a forma de capital imperialismo, segundo Fontes (2012)? A realidade global das diversas formas de expropriação deixou de ser localizada em países periféricos, atingindo todas as regiões do mundo e se refletindo cada vez mais, já que

A ameaça recorrente do desemprego aprofunda-se nos países centrais por meio da expropriação de direitos que limitavam a disponibilização da força de trabalho; modificações perversas nas modalidades de contratação de força de trabalho intensificam-se indiscriminadamente. Aprofundam-se a disponibilidade permanente, 'livre', de enorme parcela da força de trabalho, e o fenômeno vem ocorrendo também entre estratos 


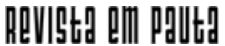

\} A CRISE DO CAPITAL E RELAÇÕES - GOMES, M. R. B. \}

DOI: $10.12957 /$ REP.2019.45241

de trabalhadores que se acreditavam protegidos de tal eventualidade.

Recompõem-se duras hierarquias no processo de trabalho, de maneira a sobrepor a já acirrada concorrência imposta pelo capital de forma difusa e esparsa, como 'necessidade natural', uma concorrência interna, entre trabalhadores com direitos contratuais profundamente diversos e, mesmo, desprovidos de direitos associados ao trabalho. (FONTES, 2012, p. 66).

Neste artigo, enfatizamos os aspectos da crise relativos às mudanças no trabalho, pois suas múltiplas dimensões não podem ser abordadas em sua totalidade nos limites deste texto. Porém, as expropriações dos direitos dos trabalhadores são fundamentais para a análise dos processos de informalização, precarização e externalização do Serviço Social nas empresas. Fontes (2012) denomina as expropriações atuais de expropriações secundárias, uma vez que os trabalhadores já não possuem mais os meios de produção, mas sim alguns direitos; esses vêm sendo extraídos gradativamente pelos capitalistas com grande suporte estatal, amparado por segmentos dos poderes legislativo e judiciário.

Para Mészáros (2009), não há remédio para as crises capitalistas, pois suas "soluções" têm historicamente demonstrado continuidade dos problemas e seu agravamento. Acompanhando-o, Antunes (1999) afirma que o capitalismo ingressa em uma nova fase, sem intervalos cíclicos entre expansão e recessão, com precipitações cada vez mais frequentes e contínuas. Trata-se, portanto, de uma crise permanente na própria realização do valor.

O discurso em torno da "confiança", da "falta dela" ou até mesmo sobre a "superconfiança" tem sido um dos mais presentes no debate sobre a crise capitalista. Porém, ainda há recusa dos capitalistas em reconhecer (ou demonstrar esse reconhecimento) a gravidade da crise atual e de seus impactos, assim como sua natureza, independente da presença ou ausência de confiança no mercado. Esses discursos tentam obscurecer a realidade, mas se demonstram insustentáveis diante dos dados reais.

Mészáros (2009) aponta o alto índice de desemprego e o fechamento de fábricas nos Estados Unidos como exemplos de inconsistência da liberdade e da eficiência de mercado valorizadas no discurso capitalista, mas que de fato não existem, porque o Estado é solicitado a atender às demandas de "salvar o sistema". Esse fato foi publicado em exemplar do The Economist, em 11 de outubro de 2008, ainda que esse discurso seja contraditório e estranho. Em seu editorial, menciona-se a perda de 150.000 empregos norte-americanos em setembro, um recorde desde 2003, e a queda das vendas de automóveis pela perda do poder aquisitivo de compradores, com o fechamento temporário de algumas fábricas da General Motors na Europa (THE ECONOMIST, 2008). Dessa forma, a conta a ser paga tem sido socializada por vários países e os defensores do "livre mercado" se distanciam desse discurso no momento que lhes interessa. Essa tem sido uma das inconsistências entre o ideário neoliberal e o processo de neoliberalização apontadas por Harvey (2008). 


\section{ReVIStg a d P p putt}

\} A CRISE DO CAPITAL E RELAÇÕES - GOMES, M. R. B. \}

DOI: $10.12957 /$ REP.2019.45241

Esses mecanismos de dominação do capital acontecem de modo articulado entre os países centrais e periféricos, com funções específicas que variam conforme a formação sócio-histórica e cultural de cada região. No Brasil, apesar de direitos sociais não terem sido constituídos como nos países de capitalismo central, muitos retrocessos têm ocorrido. Podemos destacar o ataque às políticas públicas de diferentes modos articulados, dentre eles: político-ideológico, redução de orçamento, privatização disfarçada, políticas assistenciais minimalistas, proposta de reforma previdenciária. É possível, ainda, identificar a nítida redução dos direitos trabaIhistas por meio de contrarreformas e do apelo ao empreendedorismo como caminho de liberdade e possibilidade de reprodução da força de trabalho, além do trabalho voluntário.

Tais acontecimentos trazem consequências para o Serviço Social que ultrapassam os aspectos materiais imediatos, como redução salarial, fragilidade do vínculo de trabalho e possibilidade de substituição dos postos de trabalho. $\mathrm{O}$ modo de exercer as funções profissionais pode ser atingido com repercussões na qualidade dos serviços prestados, tornando-os mais fragmentados, pontuais e individualizados, uma vez que esse cenário de maior subordinação profissional propicia maior controle do empregador. Essas questões repercutem nas condições de vida dos usuários e interferem nas demandas e respostas profissionais. Por consequência, afetam a dimensão política da profissão.

Considerando esse contexto, pensar o Serviço Social nas "consultorias empresariais" implica identificar seu papel nessa conjuntura. As perdas progressivas têm se apresentado também para os assistentes sociais, juntamente com seus processos de trabalho. Privilegiaremos, então, os impactos da crise sobre o trabalho e sua incidência na profissão do Serviço Social, destacando o apelo ao empreendedorismo e a informalidade do trabalho sob o argumento das "consultorias" empresariais.

\section{Trabalho e Serviço Social em empresas}

Para a fragmentação e precarização do trabalho têm sido utilizadas estratégias de negação da existência das classes fundamentais e da centralidade do trabalho. Nos veículos de propagação ideológica, como a imprensa, ouvimos que não vivemos mais a sociedade do emprego e sim da empregabilidade, interpretação intencionalmente simplificada para interferir na análise real da ordem societária estabelecida.

Contudo, sendo o trabalhador assalariado empregado ou "patrão" subordinado às grandes empresas, com status de pessoa jurídica, permanece a subordinação do trabalhador e da classe trabalhadora. Assim, é necessário esclarecer sobre qual interpretação de classe trabalhadora está fundamentado este artigo. 


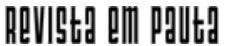

\} A CRISE DO CAPITAL E RELAÇÕES - GOMES, M. R. B. \}

DOI: $10.12957 /$ REP.2019.45241

A concepção clássica de classe, desenvolvida por Marx e Engels segundo Montaño e Durigeuto (2010) tornou-se para alguns autores uma categoria superada, alegada como insuficiente para explicar detalhadamente os desdobramentos contemporâneos. Isso porque, quando a sociedade burguesa expandia seus princípios e formas de dominação, a configuração da organização do trabalho não era tão complexa como nos dias atuais. De fato, a classe trabalhadora atual não é exatamente igual à classe trabalhadora do século XIX. Então, como se constituem as classes hoje?

Pensar nas classes trabalhadoras hoje, porém, exige ir além do proletariado e operariado, ou trabalhador fabril. O trabalhador pode ser 'produtivo' (participa na elaboração de mais-valia) ou 'improdutivo' (sem produzir mais-valia). [...] A classe envolve trabalhadores do 'chão de fábrica', de setores administrativos e de serviços no setor industrial, servidores públicos, trabalhadores autônomos, balconistas de comércio, funcionários de organizações civis, etc. Eles podem ter contratos temporários ou estáveis, ganhar salário fixo ou por comissão ou 'salário por tempo' e por peça, (Marx, 1980, p. 626-645), com direitos trabalhistas ou não. Eles podem representar o setor mais empobrecido da população, integrar grupos de consumo médio ou apresentar um elevado padrão de vida (setores baixo, médio e alto da economia). Podem possuir uma força de trabalho desqualificada ou altamente qualificada. Podem apresentar uma relação direta e formal, ou apresentar uma relação informal com o capital (a exemplo dos trabalhadores terceirizados, os camelôs, as microempresas subcontratadas, etc.). (MONTÃNO; DURIGUETO, 2010, p 94).

Com base nisso, consideramos o assistente social integrante desse grupo, ainda que desenvolva atividades de forma terceirizada e externa à instituição contratante, como ocorre na área empresarial a partir da década de 1990.

O Serviço Social em empresa não é novo. Desde a década de 1940, assistentes sociais atuam nesses espaços sócio-ocupacionais sem que suas requisições institucionais, demandas dos usuários e respostas profissionais se mantenham as mesmas, já que elementos de continuidade e de ruptura desse processo interferem na dinâmica societária que incide nas profissões. A autocrítica feita pela categoria profissional a partir do movimento de reconceituação e renovação propicia um acúmulo teórico capaz de questionar os objetivos e a direção política do Serviço Social, com base numa literatura crítica da sociedade capitalista. Além disso, também influencia a análise e a atuação dos assistentes sociais nos diferentes espaços sócio-ocupacionais.

Inicialmente, o Serviço Social em empresa tinha como requisição do empregador por funções técnicas e políticas de controle da classe trabalhadora com aparente visão humanitária. O objetivo central era formar um trabalhador de "perfil" obediente e produtivo. Decorrente do processo 


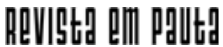

\} A CRISE DO CAPITAL E RELAÇÕES - GOMES, M. R. B. \}

DOI: $10.12957 /$ REP.2019.45241

de industrialização, o mercado de trabalho dos assistentes sociais expandiuse na década de 1970 e início dos anos 1980, quando as empresas focavam em ações sociais para trabalhadores empregados e seus familiares, embora realizassem ações para a comunidade. Nesse mesmo período, o debate teórico da profissão já se adensava em direção a uma perspectiva crítica marxista.

Na transição dos anos 1980 aos 1990, o empresariado incorpora a agenda de "responsabilidade social", expandindo suas ações diante das diferentes expressões da "questão social" e do interesse em disseminar a ideia do fracasso estatal como ação de cunho neoliberal, além de buscar a valorização da imagem institucional. Nesse contexto, assistentes sociais atuam na elaboração e execução desses programas e projetos, conforme analisa Cesar (2008). Esses programas de responsabilidade empresarial tornam-se espaços de disputa para os assistentes sociais.

Com o amadurecimento teórico-político da profissão, muitos profissionais passaram a buscar meios de redirecionar determinadas requisições na busca da qualificação dos serviços prestados à classe trabalhadora. Mesmo com avanços, os elementos conservadores presentes na profissão não foram totalmente superados, sendo remodelados pelas novas formas de gestão de inspiração toyotista implementadas a partir da década de 1990 no Brasil.

Apesar disso, Freire (2010) constata possibilidades da operacionalização da ruptura com o conservadorismo em algumas empresas selecionadas como campo de investigação, a depender do vínculo empregatício, ano de formação das profissionais, perspectiva teórico-metodológica que orienta o trabalho profissional, dentre outros aspectos.

No final dos anos 1990, resultante dos processos de reestruturação produtiva, observa-se uma configuração específica do Serviço Social em empresas, chamadas "consultorias especialistas em programas de assistência ao empregado". Esse programa inclui outras profissões (psicologia, administração, economia, direito) para o atendimento a empregados, principalmente por meio de telefone, podendo ser presencial, porém de modo pontual, fragmentado e individualizado, atendendo à lógica da acumulação flexível e de expropriação dos diretos dos trabalhadores.

As principais situações atendidas divulgadas nos sites dessas "consultorias" são: problemas financeiros, situações de falecimento domiciliar, estresse, luto, angústia, pânico e outros problemas emocionais, conflitos conjugais ou familiares, envolvimento com álcool e drogas, acompanhamento de afastados desde o início da licença até a reintegração, orientações sobre questões legais, dificuldades de relacionamento interpessoal, situações de crise (morte, suicídio, roubo, sequestro etc.), violência urbana e doméstica e orientações previdenciárias (auxílio-doença, acidente de trabalho, aposentadoria, pensão etc.).

Algumas demandas dos trabalhadores são históricas para o Serviço Social; outras indicam complexificações decorrentes do estágio atual do 


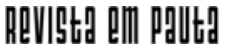

\} A CRISE DO CAPITAL E RELAÇÕES - GOMES, M. R. B. \}

DOI: $10.12957 /$ REP.2019.45241

capitalismo. Contudo, têm sido interpretadas pelas empresas e pelas "consultorias" prestadoras desses serviços (PAE) de modo cada vez mais individualizado, separado das relações de trabalho, incluindo o atendimento fora da empresa e por telefone. Isso causa distanciamento entre sujeitos atendidos e assistentes sociais ${ }^{3}$.

A hiperindividualização nas relações de trabalho, de acordo com Linhart $(2007,2014)$, é um traço gerador de processos de adoecimento predominante da gestão toyotista e um modo específico de precarização, que a autora considera uma "precarização subjetiva", mesmo nos trabalhos entendidos como protegidos. No caso das consultorias, esse aspecto é agravado tanto nos assistentes sociais que atuam em call center ou por prestação de serviços por demanda, quanto nos sujeitos atendidos.

Com o uso do termo "consultoria", remetendo a uma qualidade diferenciada, essas empresas intermediam processos de terceirização e quarteirização nas empresas, principalmente na área de recursos humanos, exercendo maior controle sobre o trabalho dos assistentes sociais, achatando salários e reduzindo a relativa autonomia dos profissionais. Para os assistentes sociais, é essencial que sua condição de profissional integrante da classe trabalhadora seja percebida como aspecto político importante nas relações capital-trabalho, independente do vínculo de emprego.

Entre os desafios e dificuldades postos à profissão, o conservadorismo, historicamente presente no Serviço Social, é um elemento central que contrapõe os avanços da profissão, pois novas bases de configuração, vínculos e condições de trabalho tendem a escamotear os reais objetivos capitalistas aparentemente sofisticados e modernos. Essa aparência tem sido traduzida em ações profissionais que atendem aos pressupostos gerencialistas, pautados em eficiência, eficácia, agilidade, suposta objetividade e neutralidade técnica, com possibilidade de quantificação dos resultados e metas.

Nesse conjunto, as novas formas de subordinação compreendem a flexibilização da produção e a intensificação da produtividade aparentemente harmônicas, diferentemente do histórico conflito entre patrões e empregados. A apropriação pelo capital das denominadas "consultorias", ocultando os processos de terceirização e quarteirização nessa contratação intermediada, muitas vezes informal, afeta a manutenção dos empregos de assistentes sociais e suas condições para resistência à ampliação das formas de exploração do trabalho. Apesar disso, não é a única forma de degradação dos direitos trabalhistas, mas uma das mais sofisticadas na omissão da real condição desses trabalhadores e trabalhadoras.

${ }^{3}$ Informações adquiridas em sites de domínio público de pequenas e grandes empresas. 


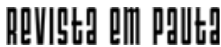

\} A CRISE DO CAPITAL E RELAÇÕES - GOMES, M. R. B. \}

DOI: $10.12957 /$ REP.2019.45241

\section{Considerações finais}

Conforme mencionado, a crise do capital incide no modo de vida das pessoas, afetando de diferentes formas a classe trabalhadora. Os assistentes sociais têm participado dessas transformações - como classe trabalhadora - em todos os espaços sócio-ocupacionais. Faz-se necessário o reconhecimento da condição de classe trabalhadora como um aspecto político fundamental para a criação de estratégias de resistência e proteção social. Conforme indicado por Linhart (2007), o isolamento tem sido um dos motivos de adoecimento físico e mental dos trabalhadores.

O universo que compõe as empresas é amplo e muito diversificado, não sendo homogêneas as mudanças nas contratações dos assistentes sociais, bem como nas requisições profissionais. Apesar disso, é necessário ter clareza de que a lógica toyotista incide sobre a organização dessas instituições mesmo quando as "consultorias" prestam serviços externos à instituição, fragmentando o trabalho e a categoria profissional, que se enfraquece como classe.

As atividades reconhecidas como atribuições profissionais têm se tornado produtos e serviços comercializados no mercado de trabalho para o aumento da lucratividade dos donos das empresas terceirizadas. Trata-se da mercantilização dos serviços prestados pelos assistentes sociais, entre eles, atividades burocráticas, atendimentos sociais, relatórios profissionais, programas e projetos etc.

Com as reformas previdenciária e trabalhista em curso no Brasil, há tendência de ampliação da precarização do trabalho e da vida dos trabalhadores de um modo geral. No trabalho dos assistentes sociais em empresas, as "consultorias" tendem a ser ampliadas, favorecendo a redução das fronteiras entre formalidade e informalidade. Por outro lado, nesse modo de inserção ocupacional a qualificação profissional deixa de ser suficiente para o acesso a um trabalho protegido, mas se mantém indispensável para a realização de serviços fragmentados transformados em mercadorias. Com isso, o caráter político-ideológico individualizante da organização do trabalho do assistente social e também do modo de atendimento tem se tornado outro agravante.

Em síntese, o que é chamado de "consultoria" nas empresas tem sido um mecanismo de redução de custos com a força de trabalho, tornando os vínculos cada vez mais instáveis e desprotegidos. O apelo ao status de "consultor", "empreendedor" e de trabalhador "livre" legitima perdas e expropriações dos direitos do trabalho, atendendo principalmente às demandas dos capitalistas de ampliação de lucro e acumulação de capitais.

Com essas reflexões, encerramos este artigo propondo uma crítica ao modo de precarização do trabalho nas empresas, e não aos trabalhadores contratados por elas. Defendemos como estratégia principal o investimento em conhecimento teórico-metodológico, ético-político e técnico-operativo 


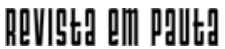

\} A CRISE DO CAPITAL E RELAÇÕES - GOMES, M. R. B. \}

DOI: $10.12957 /$ REP.2019.45241

de modo articulado, valorizando a troca entre os pares de trabalho da mesma área profissional, assim como de outras áreas. A busca por articulação dentro e fora das instituições de trabalho, valorizando a participação de espaços coletivos, reduz o isolamento e a fragmentação da categoria profissional tão útil ao capital. 


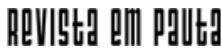

\} A CRISE DO CAPITAL E RELAÇÕES - GOMES, M. R. B. \}

DOI: $10.12957 /$ REP.2019.45241

\section{Referências}

ANTUNES, R. Os sentidos do trabalho. Ensaio sobre a afirmação e a negação do trabalho. São Paulo: Boitempo, 1999.

AMARAL, A.; CESAR, M. O trabalho do assistente social nas empresas capitalistas. São Paul0: Cortez, 1998.

CESAR, M. Empresa cidadã. Uma estratégia de hegemonia. São Paulo: Cortez, 2008.

FONTES, V. O Brasil e o capital imperialismo. Rio de Janeiro: Fundação Oswaldo Cruz, 2012.

FREIRE, L. M. B. O Serviço Social na reestruturação produtiva. Espaços. Programas, direções e processos do trabalho profissional. São Paulo: Cortez, 2010.

HARVEY, D. O novo imperialismo. São Paulo: Loyola, 2004.

HARVEY, D. O Neoliberalismo. História e implicações. São Paulo: Loyola, 2008.

IAMAMOTO, M. V.; CARVALHO, R. Relações Sociais e Serviço Social no Brasil. Esboço de uma interpretação histórico-metodológica. São Paulo: Cortez, 2013.

LINHART. D. A desmedida do capital. São Paulo: Boitempo, 2007.

LINHART. D. Modernização e precarização da vida no trabalho. In: ANTUNES, R. (Org.). Riqueza e miséria do trabalho no Brasil. Vol. III. São Paulo: Boitempo, 2014.

MANDEL, E. A crise do capital: os fatos e sua interpretação marxista. São Paulo: Ensaio, 1990.

MARX, K. O capital. Crítica da economia política. Rio de Janeiro: Civilização Brasileira, 1975.

MÉSZÁROS, I. A crise estrutural do capital. São Paulo: Boitempo, 2009.

MONTÃNO, C.; DURIGUETO, M. L. Estado, Classe e Movimento Social. São Paulo: Cortez, 2010.

MOTA, A. E. Cultura da crise e seguridade social. Um estudo sobre tendências da previdência e da assistência social brasileira nos anos 80 e 90. São Paulo: Cortez, 1995.

MOTA, A. E.; AMARAL A. S. Reestruturação do capital, fragmentação do trabalho e Serviço Social. In: MOTA, A. E. (Org.). A nova fábrica de consensos. Ensaios sobre a reestruturação empresarial, o trabalho e as demandas ao Serviço Social, São Paulo: Cortez, 1998. 


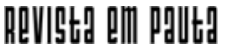

\} A CRISE DO CAPITAL E RELAÇÕES - GOMES, M. R. B. \}

DOI: $10.12957 /$ REP.2019.45241

NETTO, J. P. Transformações Societárias e Serviço Social: notas para uma análise da profissão no Brasil. Serviço Social \& Sociedade, n. 50. São Paulo: Cortez, 1996.

NETTO, J. P.; BRAZ, M. Economia política, uma introdução crítica. São Paulo: Cortez, 2007.

PASTORINI, A.; GALIZIA, S. A redefinição do padrão de proteção social brasileiro. In: Estudos de Política e Teoria Social, Praia Vermelha, n. 14, Programa de Pós-graduação em Serviço Social. UFRJ. Rio de Janeiro, 2006.

DOI: $10.12957 /$ rep.2019.45241

Recebido em 06 de fevereiro de 2019.

Aprovado para publicação em 17 de maio de 2019.

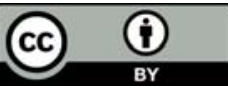

A Revista Em Pauta: Teoria Social e Realidade Contemporânea está licenciada com uma Licença Creative Commons Atribuição 4.0 Internacional. 